\title{
Tool wear characteristics of oil palm empty fruit bunch particleboard
}

\begin{abstract}
A series of machining experiments on the Oil-Palm Empty Fruit Bunch (OPEFB) particleboard were carried out using a $\mathrm{CNC}$ router, to evaluate the tool wearing properties of the composite in comparison to the conventional wood-material particleboard. A single-fluted tungsten-carbide router bit (12 mm $\varphi, 18000 \mathrm{rpm})$, with a rake angle of $15^{\circ}$ was used in this experiment, in which the depth of cut was $1.5 \mathrm{~mm}$ and feed speed was $4.5 \mathrm{~m}$ min-1. The router bit machined the edge of the board, moving along the full length before returning to repeat the cycle. The tool was examined for the extent of wear after complete failure had occurred. The result found that the wear pattern was similar in the oil-palm based particleboard and the wood-based particleboard, but the former was twice more abrasive compared to the latter. Microscopic examination of the cutter edge revealed greater incidence of micro-fracture when cutting the oil-palm based particleboard, indicating the presence of hard impurities in the composite. From an economic perspective, the tooling cost for machining oil-palm based particleboard is estimated to be twice of the cost for machining wood-based particleboard. This study shows that the machining properties of oil-palm based particleboard will be a primary concern, if the board is to find widespread application as a potential substitute for wood-based particleboard.
\end{abstract}

Keyword: Oil palm; Particleboard; Tool wear; Micro-fracture; Process economics 